7th International Symposium on Superalloy 718 and Derivatives Edited by: E.A. Ott, J.R. Groh, A. Banik, I. Dempster, T.P. Gabb, R. Helmink, X. Liu, A. Mitchell, G.P. Sjöberg, and A. Wusatowska-Sarnek TMS (The Minerals, Metals \& Materials Society), 2010

\title{
APPLICATION OF CONFOCAL SCANNING LASER MICROSCOPE IN STUDYING SOLIDIFICATION BEHAVIOR OF ALLOY 718
}

\author{
Hongwei Song ${ }^{1}$, Zhujun Miao ${ }^{2}$, Aidang Shan ${ }^{2}$, Wenliang $\mathrm{Xu}^{1}$, Jun $\mathrm{Lu}^{1}$ \\ ${ }^{1}$ Baosteel Research Institute, Baoshan Iron \& Steel Co., Ltd.; Shanghai 201900, China \\ ${ }^{2}$ School of Materials Science \& Engineering, Shanghai Jiao Tong University; \\ Shanghai 200240, China
}

Keywords: 718, Solidification; In-situ observation, Confocal Scanning Laser Microscope, Cooling rate

\begin{abstract}
Alloy 718 has a very long history, it is still used extensively, which accounts for more than $50 \%$ of commercial superalloy productions in the world. The reason is that Alloy 718 exhibits good strength, excellent weldability and lastly, but most importantly, reasonable cost. Recently, confocal scanning laser microscope (CSLM) offers a convenient way for conducting a real-time and continuous in-situ observation of phase transformations at high temperatures. Several studies using CSLM have been reported for low carbon steel, stainless steel and metallic glass materials. The aim of this paper is to study the solidification behavior of Alloy 718 using confocal scanning laser microscope. In addition to the in-situ observation of solidification at different cooling rates, the analysis of microstructure evolution was conducted by scanning electron microscopy (SEM) and energy dispersive spectrometry (EDS). The results show that the cooling rate has a great impact on the solidification behavior of Alloy 718. Variation of secondary dendrite arm spacing, morphology change in MC carbide, and Laves phase after solidification at different cooling rates are studied in details.
\end{abstract}

\section{Introduction}

Alloy 718 is an age-hardenable wrought superalloy used for elevated temperature gas-turbine applications, which is famous for its excellent balance of properties and reasonable cost, accounting for more than $50 \%$ of commercial superalloy productions in the world [1]. With the development of land-based power generation and aircraft propulsion, scaling-up of components has become the necessity. In response to market demands the size of Alloy 718 ingot produced by VIM-ESR-VAR triple melting has increased markedly over the past 10 years [2-7]. However, the solutes segregation problem, mainly niobium segregation, is a big issue for producing large size Alloy 718 ingots. Particularly, some macrosegregations such as freckles and white spots formed during the solidification process may lead to failure of entire ingot. Therefore the indepth studies of solidification behavior of Alloy 718 are still needed.

In the past, a number of methods has been employed to study the solidification behavior of Alloy 718, including differential thermal analysis (DTA), high temperature freezing and computational modeling. Knorovsky et al., utilizing DTA, derived transformation temperatures and provided a solidification diagram for an idealized (interstitial free) Alloy 718 system [8]. Wang et al. used high temperature freezing method to keep the initial liquid state of alloy, for analyzing the original solidification process [9]. Thermo-calc and JMatPro software were also employed to calculate the liquid composition and equilibrium diagrams of Alloy 718, which can provide a variety of valuable solidification information and predict segregation during triple melting or casting [9-10]. 
Confocal scanning laser microscope (CSLM) offers a convenient way for conducting a real-time and continuous observation of phase transformations at high temperatures. Several studies using CSLM have been reported involving low carbon steel [11-14], stainless steel [15] and metallic glass materials [16]. Therefore, this novel equipment is applied to perform an in-situ observation of solidification process of Alloy 718. Furthermore, the microstructure and segregation behavior of the solidified CSLM samples are revealed in this study.

\section{Experimental Methods and Materials}

The detailed characteristics of CSLM have been described in the previous studies [11]. The shallow undulation of sample surface caused by phase transformation and small difference of reflectivity between transforming phases, which could be sensitively detected by CCD image sensor of CSLM, making it possible to observe phase transformation process at high temperatures up to $1873 \mathrm{~K}[12,17]$. Simultaneously, the real-time pictures were recorded at a rate of 30 frames per second. Figure 1 shows the basic components of a confocal scanning laser microscope (1LM21H from Lasertec Corporation), which include microscope, metallurgy furnace, monitor, computer, protective air system, vacuum pump and circular water system. The specific CSLM equipment used in the current study employs a He-Ne laser with a wavelength of $633 \mathrm{~nm}$ allowing for magnifications up to $2450 \mathrm{X}$.

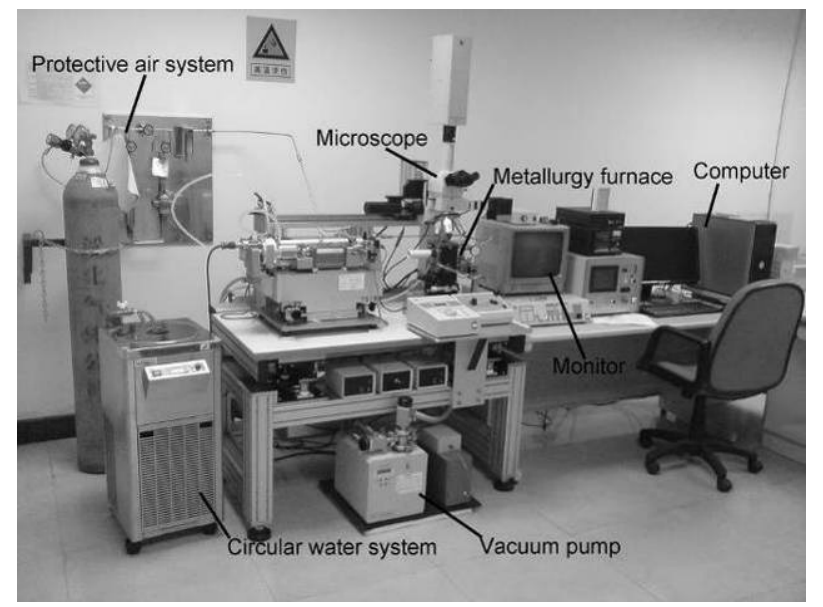

Figure 1. Components of confocal scanning laser microscope (CSLM).

Alloy 718 was produced by $10 \mathrm{~kg}$ vacuum induction melting (VIM) furnace, with composition listed in Table 1. The CSLM samples, cylindrical in shape $(4 \mathrm{~mm}$ in diameter and $3 \mathrm{~mm}$ in height), were mirror polished and placed into an alumina crucible. Then, the crucible was set in the heating position of metallurgy furnace. The temperature was controlled by a thermocouple attached to the crucible. When the heating temperature is reached, it will be kept constant within $\pm 1 \square$. The continuous ultra pure argon $(99.999 \%)$ was purged into the chamber in order to avoid the oxidation.

Table 1 Chemical compositions of Alloy 718 (mass \%)

\begin{tabular}{|c|c|c|c|c|c|c|c|c|c|}
\hline $\mathrm{C}$ & $\mathrm{P}$ & $\mathrm{B}$ & $\mathrm{Al}$ & $\mathrm{Ti}$ & $\mathrm{Mo}$ & $\mathrm{Nb}$ & $\mathrm{Cr}$ & $\mathrm{Ni}$ & $\mathrm{Fe}$ \\
\hline 0.05 & 0.004 & 0.0011 & 0.52 & 1.00 & 3.10 & 5.33 & 19.5 & 53.0 & Bal. \\
\hline
\end{tabular}

Since the purpose of this investigation is to observe the solidification process, differential scanning calorimetry (DSC) test was conducted to identify the temperatures of phase transformations during solidification, which then was the basis for setting observation 
temperatures in the CSLM experiment. Figure 2 shows the DSC curve at the cooling rate of $0.167 \mathrm{~K} / \mathrm{min}$. It may be seen in Figure 2 that the primary crystallization (first peak) took place at $1610.5 \mathrm{~K}$. The second peak and third peak were associated with precipitation of MC carbides and Laves phase. According to the above analysis, the CSLM samples were heated from room temperature to $1673 \mathrm{~K}$ in $480 \mathrm{~s}$ and be held for a further $300 \mathrm{~s}$ at $1673 \mathrm{~K}$ to obtain uniform liquid state. Afterwards, three cooling rates, of $0.083 \mathrm{~K} / \mathrm{min}, 1.67 \mathrm{~K} / \mathrm{min}$ and $3.33 \mathrm{~K} / \mathrm{min}$ were investigated, as shown in Figure 3. Finally, the furnace was powered-off at $1373 \mathrm{~K}$ to let the samples cool to room temperature.

Microstructural analysis was performed on polished longitudinal sections of three specimens. MC carbide morphology was examined by light microscope (LM, Leica DM-6000), and Laves phase was examined on electro-etched surfaces in scanning electron microscope (SEM, TescanVega) equipped with an energy dispersive spectrometry micro-analyzer (EDS, Bruker).

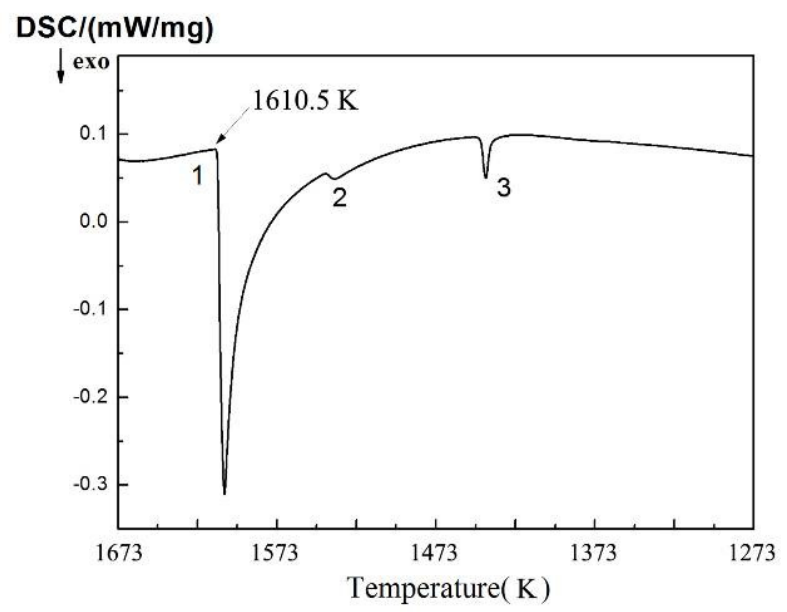

Figure 2. Differential scanning calorimetry curve of the test alloy.

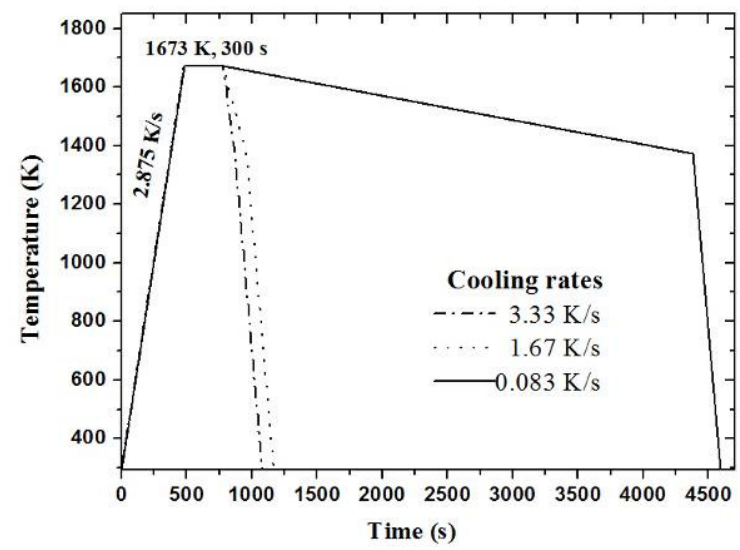

Figure 3. Thermal cycles employed in current study. 


\section{Results and Analysis}

$\underline{\text { Solidification process at a cooling rate of } 1.67 \mathrm{~K} / \mathrm{min}}$

Figure 4 illustrates the solidification process for Alloy 718 at a cooling rate of $1.67 \mathrm{~K} / \mathrm{min}$, obtained by CSLM. The temperature changes and real times are also displayed on the continuously recorded pictures. In the previous research, the crucible which holds the sample can provide a favorable site for heterogeneous nucleation in AISI304 stainless steel [15]. Similarly, seen from Figure 4, it is inferred that the solidification of Alloy 718 has commenced below the surface of the opaque melt and is gradually being revealed at the melt surface. With the temperature decrease the solid-liquid interface is moving toward inter-dendritic region coupled with the progressive decrease of the liquid pool areas. However, it is found that some remaining liquid still exists at the final solidification stage of primary crystallization. It is believed that these remaining liquid areas are the most segregated regions and therefore this severe segregation leads to the reduction of solidifying temperatures, which can explain why the remaining liquid can not solidify for long time in the CSLM observation. Unfortunately, the formation of Laves phase in the inter-dendritic region can not be observed because of the equipment capability.

Since progressive decrease of the liquid pool areas happens in the solidification process, it is feasible to acquire the liquid fraction at the free surface by calculating the liquid area of each picture recorded in CSLM observation. Here, AutoCAD software is used to calculate the liquid area percentage and yield the relationship between liquid fraction and time as well as liquid fraction and temperature. Thus, the Avrami equation [18] is utilized for fitting the curve and Figure 5 presents the results. The equation utilized to calculate the liquid fraction as a function of temperature is as follows:

$$
f_{L}=1-\exp \left[-2.21 \times 10^{-7}(T-1543)^{4.5}\right]
$$

The cooling rate in the present experiment is $1.67 \mathrm{~K} / \mathrm{min}$ and the onset of solidification temperature is $1608 \mathrm{~K}$, therefore the temperature $(T, \mathrm{~K})$ dependence of time $(t, \mathrm{~s})$ is according to the following equation:

$$
T=1608-\frac{5}{3} t
$$

Therefore, the liquid fraction as a function of time can be obtained:

$$
f_{L}=1-\exp \left[-2.21 \times 10^{-7}\left(65-\frac{5}{3} t\right)^{4.5}\right]
$$

It is obviously seen from Figure 5 that there are three stages for $\mathrm{L} \rightarrow \gamma$ solidification, which are here named as initial stage, stable stage and final stage respectively. After linear fitting of each stage, comparison can be made to demonstrate the characteristic of each stage, shown in Figure 6. First, in the initial stage of $\mathrm{L} \rightarrow \gamma$ solidification process, the solutes segregated little by little in the front edge of $\mathrm{L} / \gamma$ interface, resulting in the reduction of liquidus temperature. The $\mathrm{L} \rightarrow \gamma$ phase transformation can only happen with the further decreasing of temperature. So, $\gamma$ growing rate is $0.004 \mathrm{~s}^{-1}$ for this stage. Secondly, $\mathrm{L} \rightarrow \gamma$ transformation undergoes a more stable stage. At this stage, the $\mathrm{L} / \gamma$ interface is moving in a stationary speed and the $\gamma$ growing rate is $0.083 \mathrm{~s}^{-1}$, almost 20 higher of initial stage. Finally, when the remaining liquid pool areas become little, the phase transformation comes to the final stage. The segregated solutes in remaining liquid pool can not diffuse across the $\mathrm{L} / \gamma$ interface, so the segregation degree in the remaining liquid is rising dramatically, which leads to the low speed solidification again. For the last stage, $\gamma$ growing rate is $0.016 \mathrm{~s}^{-1}$. 


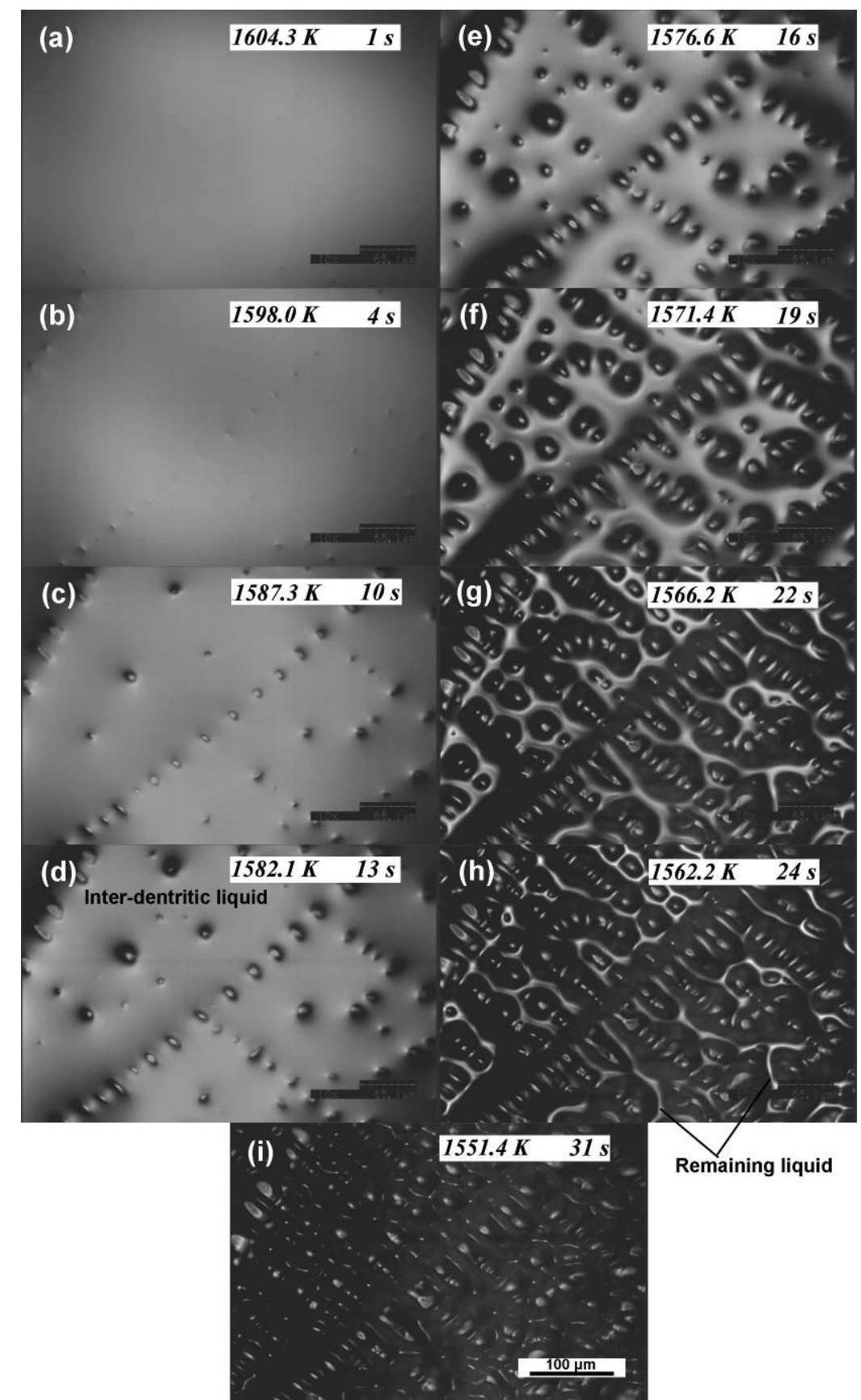

Figure 4. Confocal scanning laser microscopy in-situ observation of solidification process in Alloy 718 at cooling rate $1.67 \mathrm{~K} / \mathrm{min}$. 


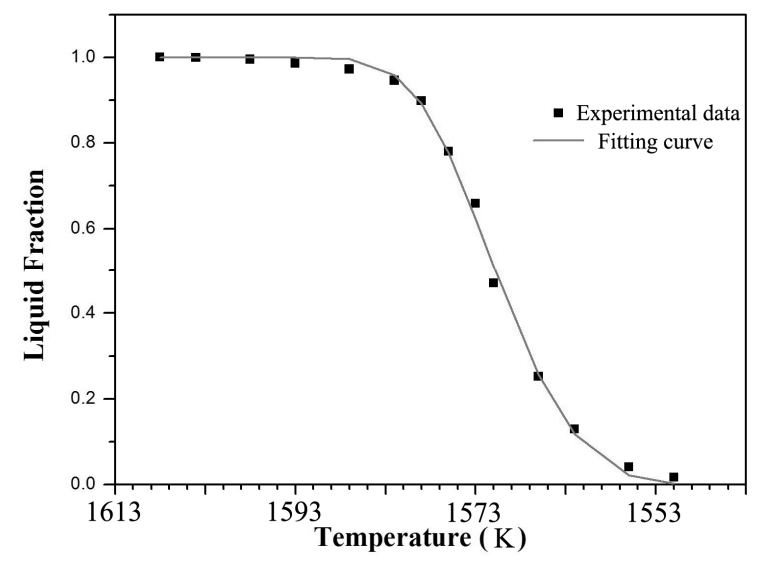

Figure 5. Fitted curve of liquid fraction as a function of temperature at cooling rate $1.67 \mathrm{~K} / \mathrm{min}$.

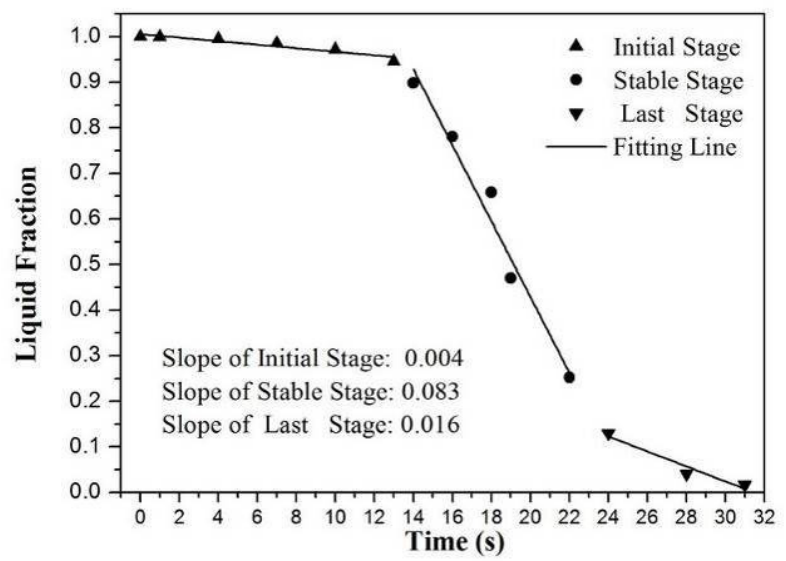

Figure 6. Three stages for $\mathrm{L} \rightarrow \gamma$ transformation at cooling rate $1.67 \mathrm{~K} / \mathrm{min}$.

Microstructure analysis on solidified CSLM sample (cooling rate: $1.67 \mathrm{~K} / \mathrm{min}$ )

Figure 7(a) shows the typical microstructure of solidified CSLM sample. It can be seen that a lot of blocky Laves phase exist in the inter-dendritic region. MC carbides are also observed around the Laves phase, also in the inter-dendritic region. Figures 7(b)-(d) present the EDS spectrums of three different locations and approximate chemical compositions are listed in Table II. According to Table 2, Nb and Mo are strongly enriched in the Laves phase. On the other hand, $\mathrm{Nb}$ and Mo are obviously poor in the area of dendrite core. MC carbide is mainly composed of two elements: $\mathrm{Nb}$ and $\mathrm{Ti}$. 

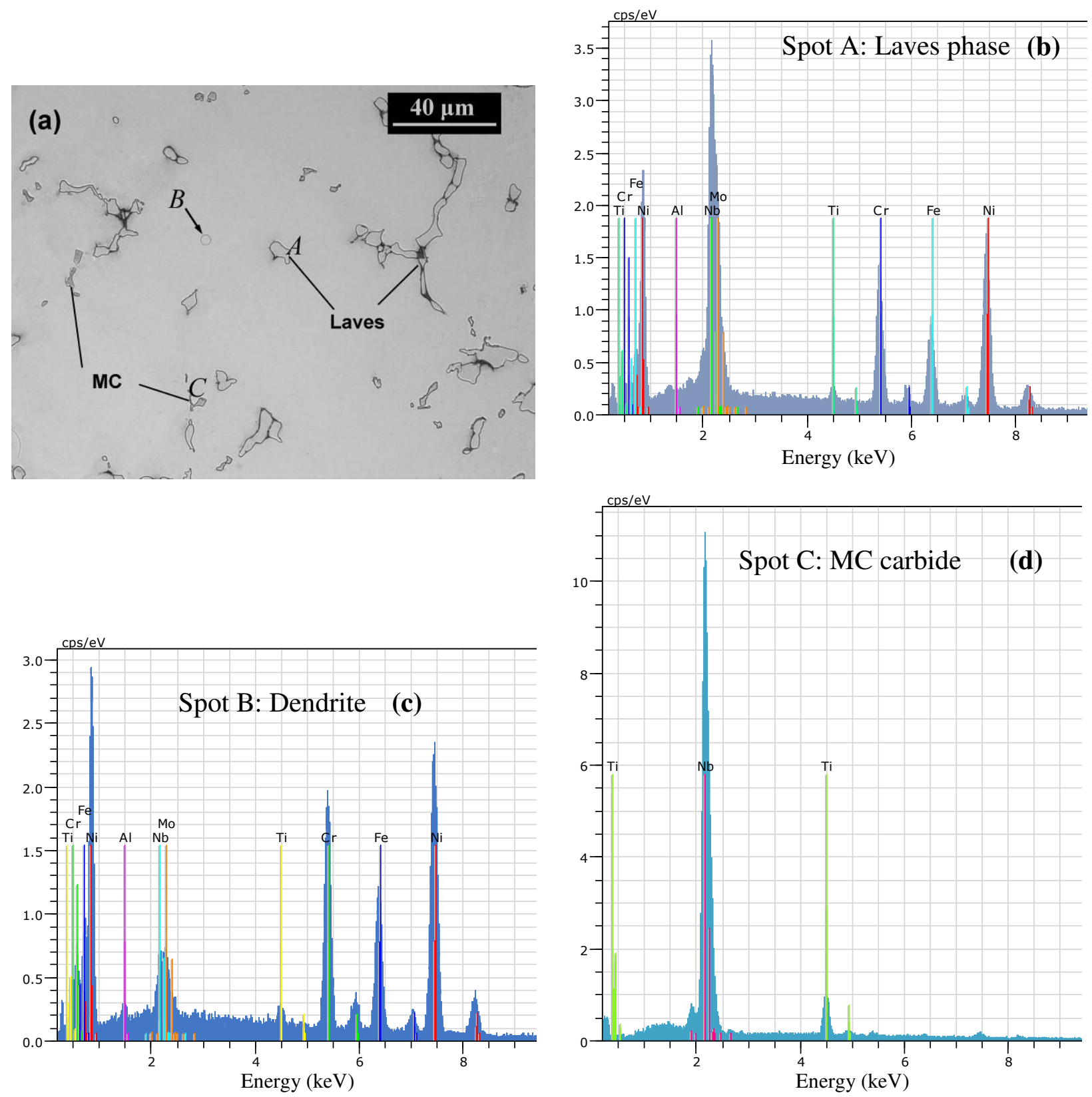

Figure 7. The microstructure of solidified sample after CSLM experiment (a) and the EDS spectrums of the Laves phase (b), dendrite core (c) and MC carbide (d).

Table 2 Chemical compositions of representative phases or locations in solidified CSLM sample

\begin{tabular}{|c|c|c|c|c|c|c|c|}
\hline \multirow{2}{*}{ Location } & \multicolumn{7}{|c|}{ Chemistry (mass \%) } \\
\cline { 2 - 8 } & $\mathrm{Ni}$ & $\mathrm{Cr}$ & $\mathrm{Fe}$ & $\mathrm{Nb}$ & $\mathrm{Mo}$ & $\mathrm{Ti}$ & $\mathrm{Al}$ \\
\hline Spot A & 35.17 & 14.48 & 13.53 & 28.23 & 7.01 & 0.98 & 0.6 \\
\hline Spot B & 52.95 & 21.01 & 18.89 & 3.51 & 2.43 & 0.71 & 0.5 \\
\hline Spot C & - & - & - & 92.39 & - & 7.61 & - \\
\hline
\end{tabular}


Figure 8 shows the solidification process at three different cooling rates. It is evident that secondary dendrite arm spacing becomes finer with increasing cooling rate.

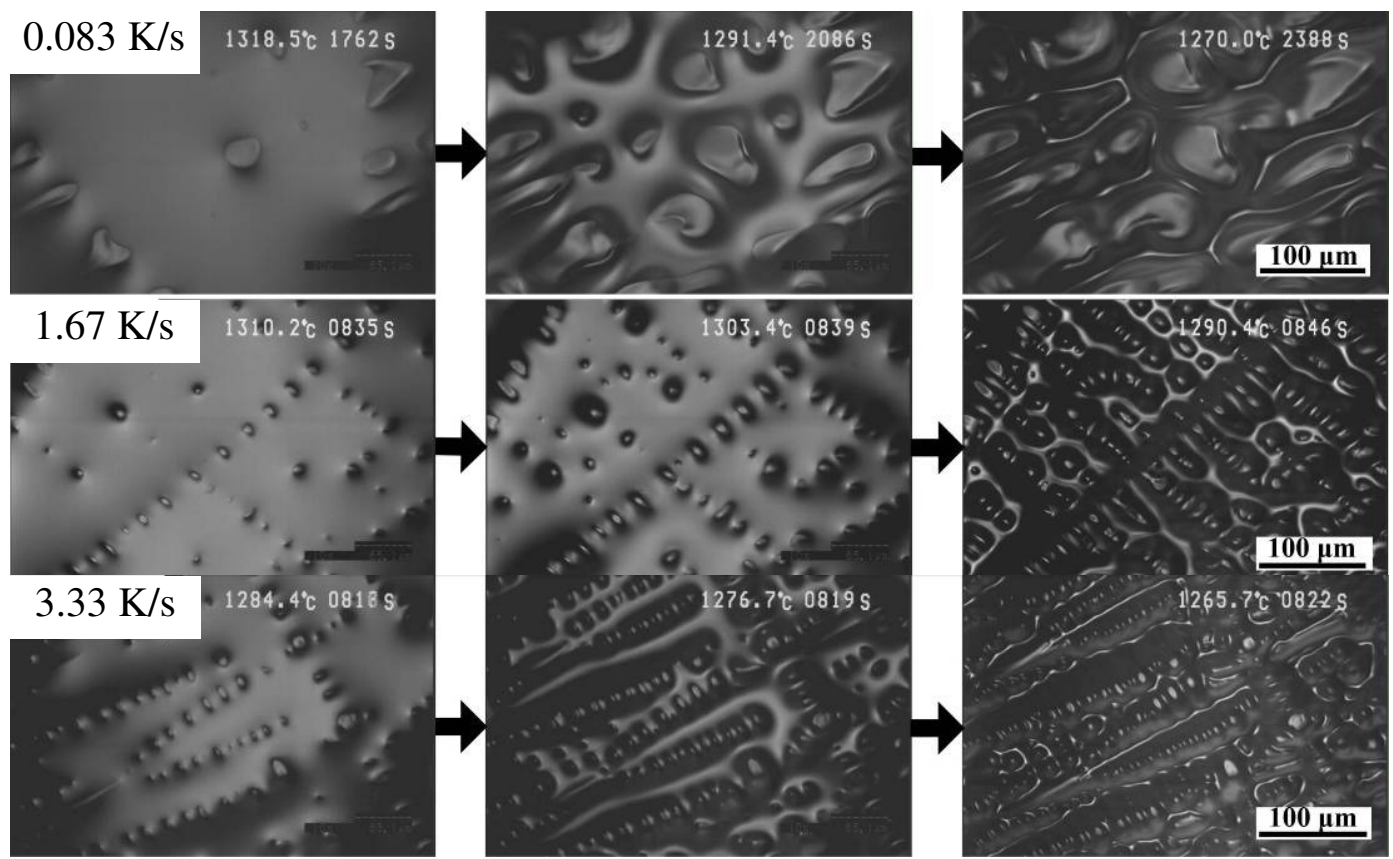

Figure 8. Solidification process at three cooling rates $(0.083 \mathrm{~K} / \mathrm{min}, 1.67 \mathrm{~K} / \mathrm{min}$, and 3.33

$\mathrm{K} / \mathrm{min}$ ).

The secondary dendrite arm spacing (SDAS) is an important parameter in the solidified dendrite structures. Considering the direct impact of cooling rates, the SDAS will differ from each other for various cooling rates. Therefore, the variation of SDAS is investigated firstly. In order to obtain precise results, various levels of cooling rates are applied. Apart from the three cooling rates mentioned above, $0.167 \mathrm{~K} / \mathrm{min}, 0.5 \mathrm{~K} / \mathrm{min}$ and $0.833 \mathrm{~K} / \mathrm{min}$ are also studied. In a classical equation given as Eq.4 [19], SDAS is available as a function of cooling rates. Figure 9(a) shows the values of SDAS, which indicates that the measured SDAS are in a good agreement with the classical equation.

$$
L=\beta(\dot{T})^{-1 / 3}
$$

Where $\mathrm{L}$ represents SDAS $(\mu \mathrm{m}) ; \beta$ is the constant for a fixed alloy; $\dot{T}$ is the cooling rate $(\mathrm{K} / \mathrm{min})$. The linear fitting is conducted so as to get the value of $\beta$, which is shown in Figure 9(b). On the basis of this result, the prediction on SDAS of Alloy 718 can be made by the following equation.

$$
L=183.6(\dot{T})^{-1 / 3}
$$



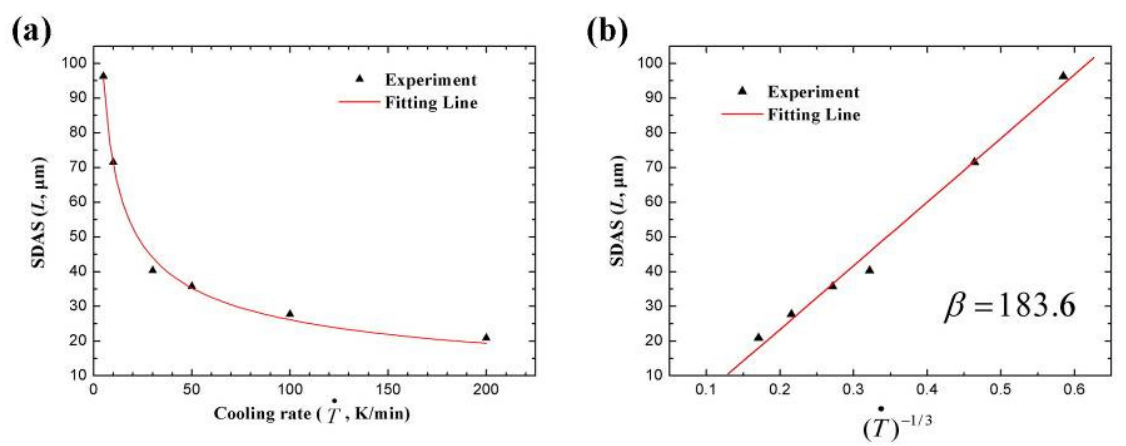

Figure 9. Secondary dendrite arm spacing at different cooling rates

As stated before, MC carbide and Laves phase are two main segregation phases formed in the solidification process of Alloy 718. Figure 10 and Figure 11 show the change of two segregation phases in morphology at three different cooling rates.

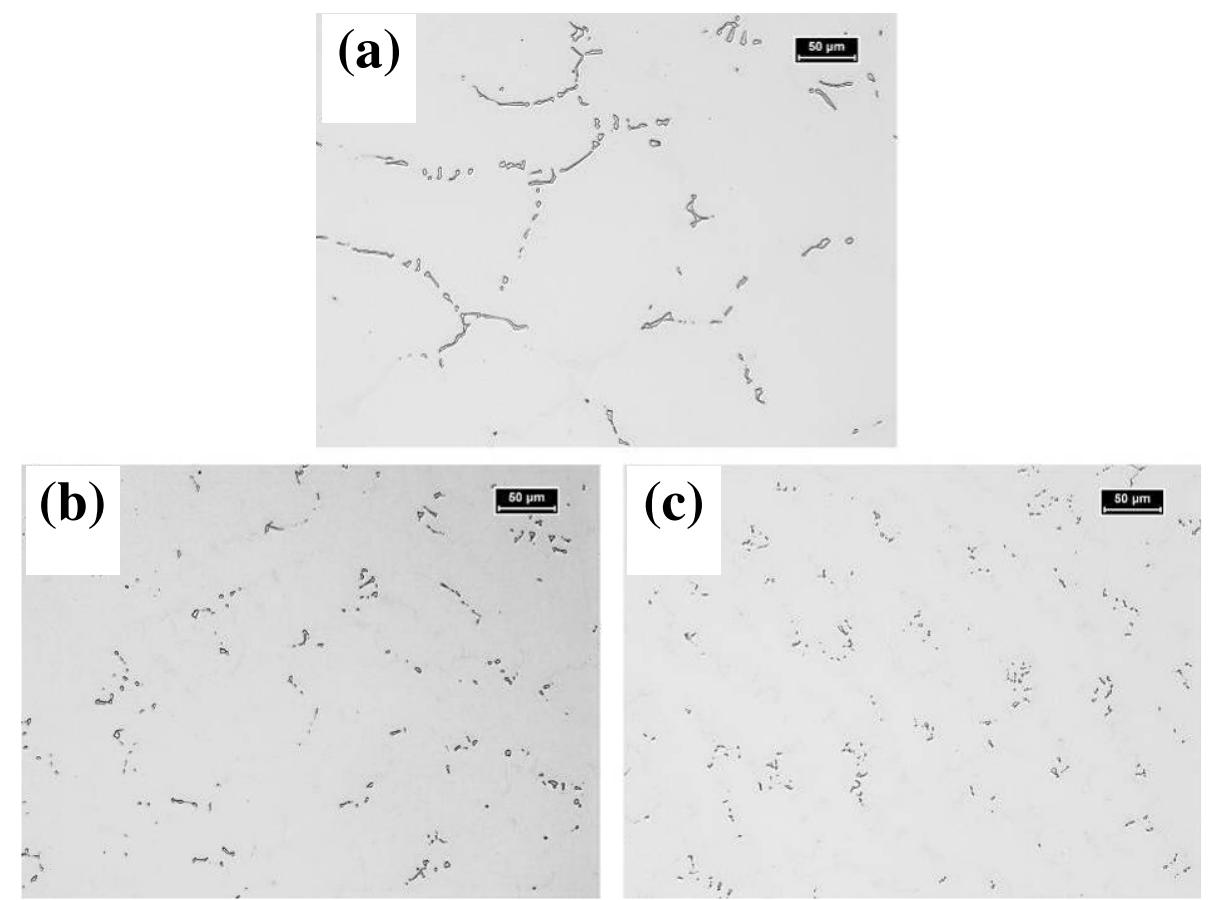

Figure 10. MC carbide morphology after solidification at various cooling rates (a) $0.083 \mathrm{~K} / \mathrm{min}$, (b) $1.67 \mathrm{~K} / \mathrm{min}$, (c) $3.33 \mathrm{~K} / \mathrm{min}$.

In the case of low cooling rate $(0.083 \mathrm{~K} / \mathrm{min})$, it is seen in in-situ observation that the remaining liquid contacts each other, which can form segregation phases in large size eventually. There are two reasons to be addressed. Firstly, the solutes have enough time to segregate during the solidification at lower cooling rate. Secondly, relatively large SDAS gives enough room to form large segregation phases. While in the case of high cooling rate $(1.67 \mathrm{~K} / \mathrm{min}$ and $3.33 \mathrm{~K} / \mathrm{min})$, no enough time and room is provided to form large segregation phases, which ends up with small blocky phases in the inter-dendritic area. 


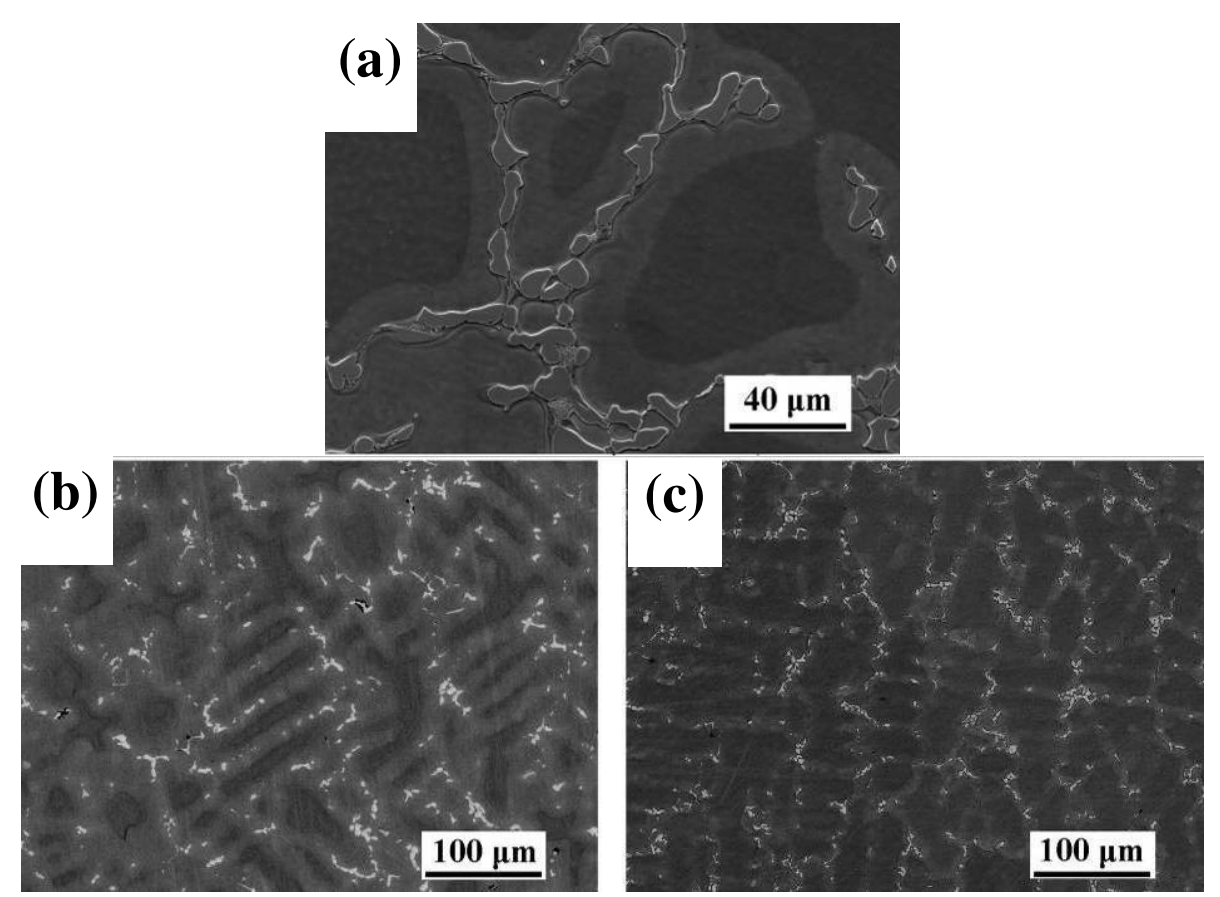

Figure 11. Laves phase morphology after solidification at various cooling rates (a) $0.083 \mathrm{~K} / \mathrm{min}-\mathrm{SE}$, (b) $1.67 \mathrm{~K} / \mathrm{min}-\mathrm{BSE}$, (c) $3.33 \mathrm{~K} / \mathrm{min}-\mathrm{BSE}$.

\section{Conclusions}

Confocal scanning laser microscope was successfully employed to investigate the Alloy 718 solidification process The microstructure evolution and segregation characteristic were also investigated at different cooling rates. The following conclusions can be made from this study:

1. According to the in-situ observation, three stages can be defined for $\mathrm{L} \rightarrow \gamma$ transformation of Alloy 718: initial stage, stable stage and last stage. When solidified at the cooling rate of 1.67 $\mathrm{K} / \mathrm{min}$, the $\gamma$ growing rates of three stages are $0.004 \mathrm{~s}^{-1}, 0.083 \mathrm{~s}^{-1}$, and $0.016 \mathrm{~s}^{-1}$, respectively.

2. The secondary dendrite arm spacing $(L, \mu \mathrm{m})$ of Alloy 718 is dependent of the cooling rate $(\mathrm{K} / \mathrm{min})$ and may be described by the following equation:

$$
L=183.6(\dot{T})^{-1 / 3}
$$

3. The cooling rate has a great impact on the morphology of MC carbide and Laves phase. The sizes of MC carbide and Laves phase are smaller with the increase of cooling rate, which is directly proved by the in-situ observation results.

\section{Acknowledgments}

This project is supported by the Major Program for the Fundamental Research of Shanghai Committee of Science and Technology, China (Grant No. 08dj1400402). Baoshan Iron \& Steel Co., Ltd. and Institute of Metal Research are also appreciated for providing financial support. The CSLM observations were conducted at advanced technology division of Baosteel Research Institute, under the supervision of Mr. Chenquan Wang. One of the authors (Zhujun Miao) would 
like to acknowledge Prof. Wenru Sun from Institute of Metal Research and Dr. WusatowskaSarnek from Pratt \& Whitney for kindly help

\section{References}

1. Decker W. T., JOM, 58(9), 2006, 32-36.

2. Carter W. T. and Forbes J. R. M., JOM, 57(4), 2005, 52-57.

3. Helms A. D., Adasczik C. B. and Jackman L.A., Superalloys 1996, ed. R. D. Kissinger et al., TMS, 1996, 427-433.

4. Schwant R. C., Thamboo S. V., Anderson A. F., Adasczik C. B., Bond B. J., Jackman L. A. and Uginet J. F., Superalloys 718, 625, 706 and Various Derivatives, ed. E.A. Loria, TMSAIME, 1997, 141-152.

5. Thamboo S. V., Schwant R. C., Yang L., Jackman L. A., Bond B. J. and Kennedy R. L., Superalloys 718, 625, 706 and Various Derivatives, ed. E.A. Loria, TMS-AIME, 2001, 5770.

6. Schwant R.C., Thamboo S.V., Yang L. and Morra M., Superalloys 718, 625, 706 and Derivatives, ed. E.A. Loria, TMS, 2005, 15-24.

7. Malara C. and Radavich J., Superalloys 718, 625, 706 and Derivatives, ed. E.A. Loria, TMS, 2005, 25-33.

8. Knorovsky G. A., Cieslak M. J., Headley T. .J., Romig A. D. and Hammetter W. F, Metall. Trans. A, 20A, 1989, 2149-2158.

9. Wang L., Dong J. X., Tian Y. L. and Zhang L., J. Univ. Sci. Technol. Beijing, 15(5), 2008, 594-599.

10. Saunders N., Guo Z., Li X., Miodownik A. P. and Schille J-Ph., Superalloys 2004, ed. K. A. Green et al., TMS, 2004, 849-858.

11. Yin H., Emi T. and Shibata H., ISIJ Int., 38(8), 1998, 794-801.

12. Yin H., Emi T. and Shibata H., Acta Mater., 47(5), 1999, 1523-1535.

13. Liu Z. Z., Kobayashi Y., Yang J., Nagai K., Kuwabara M., ISIJ Int., 46(6), 2006, 847-853. 
14. Phelan D. and Dippenaar R., ISIJ Int., 44(2), 2004, 414-421.

15. Liang G. F., Wang C. Q., Wu J. C., Zhu G. M., Yu Y. and Fang Y., Acta Metall. Sin.(Engl. Lett), 19(6), 2006, 441-448.

16. Kim J. H., Kim S. G. and Inoue A., Acta Mater., 49, 2001, 615-622.

17. Shibata H. and Emi T. Materia Jpn. (in Japanese), 36, 1997, 809-813.

18. Hu G X. and Cai X., The Fundamental of Materials Science (Shanghai: Shanghai Jiao Tong University Press, 2000), 215.

19. Flemings M. C., Solidification Processing (New York: McGraw-Hill, 1974). 